\title{
$O$ ENS TERTIO ADIACENS DE GERARDO ODON E O REALISMO PROPOSICIONAL
}

\author{
Ana Rieger Schmidt* \\ ana.rieger@gmail.com
}

RESUMO $O$ artigo aborda o tratado lógico de Geraldo Odon "De duobos communissimis principiis scientiarum" focando na noção de ens tertio adiacens: o ente significado pela totalidade da proposição e seu verificador. Odon o identifica ao sujeito dos princípios de não-contradição e terceiro excluído. $O$ ens tertio adiacens também corresponde ao primeiro objeto adequado do intelecto e ao sujeito da lógica, a qual é entendida como a primeira ciência. Na segunda parte do artigo, localizamos Odon no debate historiográfico do realismo proposicional, ao lado de Walter Burley.

Palavras-chave Geraldo Odon, ens tertio adiacens, realismo proposicional, propositio in re, Walter Burley.

ABSTRACT This paper deals with Geraldus Odonis' logical treatise "De duobus communissimis principiis scientiarum" by focusing on the concept of 'ens tertio adiacens': the being signified by the totality of the proposition and its truthmaker; Odonis identifies it to the subject of the principles of noncontradiction and excluded middle. The ens tertio adiacens also corresponds to the first adequate object of the intellect and to the subject of logic, which is understood as the first science. In the second part of the paper, we place 
Odonis in the historiographical debate of propositional realism, alongside Walter Burley.

Keywords Geraldus Odonis, ens tertio adiacens, propositional realism, propositio in re, Walter Burley.

Neste artigo nós trataremos da noção de ens tertio adiacens segundo Geraldo Odon (1285-1349) ${ }^{1}$ e suas diversas funções lógicas, tal como exposto em seu tratado lógico "De duobos communissimis principiis scientiarum"2 (escrito ca. 1320). Procuraremos dar conta dos principais argumentos de Odon chamando a atenção para os aspectos mais originais dessa obra ainda pouco conhecida pela historiografia medieval. A partir dessa apresentação, localizaremos o tratado de Odon em um debate historiográfico específico, a saber, as teorias realistas do significado proposicional no século XIV. Para tanto, procuraremos comparar os aspectos centrais da explicação odoniana do mecanismo de verificação proposicional à propositio in re de Walter Burley (c. $1275-c .1346),{ }^{3}$ lógico inglês e contemporâneo de Odon ${ }^{4}$ que apresenta, como veremos abaixo, uma teoria do significado proposicional realista. Nosso objetivo não é de estabelecer o texto de Odon como uma fonte de Burley ou vice-versa, mas tão somente identificar uma tendência comum no que toca à solução do problema da verificação de proposições. Em particular, concentrarnos-emos nos casos de proposições "não standard", isto é, proposições cujos termos (sujeito e/ou predicado) designam não-existentes (por exemplo, 'César não existe' e 'a quimera é uma quimera'), na medida em que elas colocam em questão a associação entre significação e existência. Em outras palavras, concentrar-nos-emos sobre os problemas de 'referência vazia' ${ }^{5}$ relacionados à significação proposicional. Convém notar que se inscrevem ainda na

1 Odon foi mestre em teologia em Paris, onde ele ensina as Sentenças entre 1326 e 1328; seu comentário incorpora diversas teses dos tratados lógicos anteriores, entre eles o De principiis scientiarum.

2 G. Odon, 1997. Sobre a filosofia de Odon, conferir o excelente volume da revista Vivarium 47, 2-3, 2009, organizado por Duba, W. et Schabel. A mesma obra foi publicada separadamente como Duba, 2009.

3 Burley se torna mestre de artes em torno de $1301 \mathrm{em}$ Oxford e em seguida mestre em teologia em Paris em torno de 1324. Sua carreira coincide com a de Guilherme de Ockham (ca. 1286-1347), contra quem Burley opõe uma teoria da proposição fortemente antinominalista.

$4 \mathrm{O}$ ano acadêmico de 1316-17 é considerado como o terminus post quem. Odon teria ensinado as Sentenças em Toulouse, de onde provêm as primeiras reportationes. Sabemos que durante sua estadia toulousiana, Odon participou de uma disputatio com Walter Burley. Cf. C. Schabel, 2004, pp. 124-125. Cf. A. de Libera, 2002. 
mencionada via realista do século XIV: Gregório de Rimini (c. 1300-1358) - cuja posição sobre os complexe significabilia ${ }^{6}$ se tornou bem conhecida (e criticada $^{7}$-, João Wyclif (ca. 1326-1384) e Ricardo Brinkley (fl. 1360) ${ }^{8}$ Não poderemos, no entanto, tratar desses casos aqui. Nosso critério de comparação prioriza a proximidade temporal e doutrinal entre Odon e Burley, na medida em que elas nos permitem considerá-los como prováveis interlocutores, ainda que não haja registro de um debate entre Odon e Burley com relação à problemática apreciada neste artigo.

Como ponto de partida, pensamos ser importante começarmos pela explicitação do que entendemos por "realismo proposicional" neste contexto.

\section{Definição de realismo proposicional}

Segundo a teoria aristotélica da verdade como correspondência, "assim como a coisa (pragma, res) é ou não é, uma oração (proposição) é dita verdadeira ou falsa". Se essa definição de verdade foi estabelecida pela tradição de comentários a Aristóteles e seguida por todas as correntes lógicas, a natureza desta correspondência não foi sempre entendida da mesma maneira. A questão “ao quê corresponde a proposição?” recebeu ao menos dois tipos de resposta: enquanto os nominalistas reduzem o significado da proposição aos significados dos seus termos, os realistas admitem haver algo que corresponda ao significado da totalidade da proposição, o qual é irredutível aos significados dos termos que a compõem. De uma maneira geral, nós caracterizamos uma teoria realista da proposição pela aceitação dos três pontos seguintes:

(i) A proposição mental possui um significado próprio;

(ii) $\mathrm{O}$ significado próprio não possui o mesmo modo de ser da proposição mental. O que implica:

(iii) A admissão de entidades extramentais às quais tais significados correspondem.

6 Cf. J. Biard, 1989; J. Biard, 2004; P. Bermon, 2007.

7 João Buridan (1295-1358), João de Mirecourt (lê as "Sentenças" em 1343-1345), André de Neufchâteau (fl. 1360), Marsílio d'Inghen (1340-1396) e Pedro de Ailly (1350-1420), estão dentre os filósofos que criticam a doutrina dos complexe significabilia, defendida por Rimini e inicialmente defendida por Adão Wodeham, no interior de um debate sobre o objeto do conhecimento científico (mais precisamente da proposição que constitui a conclusão de um silogismo) iniciada por Ockham nos anos 1320.

8 Cf. L. Cesalli (2007a), para uma explicação detalhada das teorias bem como a bibliografia referente a João Wyclif e Ricardo Brinkley.

9 Aristóteles, "Categorias", 5, 4b8-10 (Aristoteles Latinus I.1-5, p. 13): "Eo enim quo res est vel non est, eo oratio vel vera vel falsa dicitur". 


\section{Argumento principal do tratado "De principiis scientiarum"}

Os filósofos e teólogos medievais herdam um princípio, de origem aristotélica, que exprime os limites da significação e que consiste no mais certo conhecimento - com efeito, ninguém pode se enganar a seu respeito. O princípio de não-contradição recebe diversas formulações, como est impossibile eidem simul inesse et non inesse idem, impossibile sit simul esse et non esse, ou ainda na sua forma acoplada ao princípio do terceiro excluído: de quolibet esse vel non esse et de nullo simul.

O principio de não-contradição (assim como o terceiro excluído) é absolutamente incondicional. Qualquer outro princípio o pressupõe. Por isso, não é possível demonstrá-lo, pois isso pressuporia o que se procura provar. Para responder aos objetores que pensam poder negar a sua validade, Aristóteles mostra que a contradição é a aniquilação do discurso significativo. Esse princípio não pode ser negado sem ser ao mesmo tempo afirmado. ${ }^{10}$ Um princípio de tal primazia pertence tradicionalmente à ciência suprema: metafísica, primeira na hierarquia das ciências teóricas.

É justamente à determinação das propriedades dos primeiros princípios que Geraldo Odon dedica o seu tratado lógico "De duobus principiis communissimis scientiarum". No primeiro capítulo, Odon procura determinar o escopo dos princípios de não-contradição e terceiro excluído, tarefa que corresponderá àquela de encontrar um domínio dos entes que possa ser referido por toda proposição, sem que seja implicada a noção de existência ou não-existência atual. Em outras palavras, Odon busca um modo do ser que não se limite à existência meramente mental e que tampouco exija uma existência extramental, mas que combine estes dois domínios com vistas a compartilhar o escopo dos primeiros princípios. Com efeito, os escopos dos domínios do ente real (ens reale) e do ente de razão (ens rationis) se mostram insuficientemente extensos, pois enquanto o primeiro coloca a existência, o segundo coloca a não-existência atual. Odon explica essa oposição em outros termos, utilizando a expressão 'constantia' - uma noção comumente encontrada nos textos lógicos para designar a existência atual das coisas referidas pelos termos de uma proposição. Assim, enquanto o ens reale supõe a constância da coisa (constantia rei), o ens rationis supõe a sua nãoconstância. ${ }^{11}$ Ora, os primeiros princípios se aplicam a tudo aquilo que pode

10 Esta estratégia ficou conhecida como refutação elênctica. Cf. Aristóteles, "Metafísica", 1006a11-1007a20 para o princípio de não-contradição; 1008a2-b10 para o princípio de terceiro excluído.

11 Odon, 1997, I, §57, p. 347-8: "Termini horum principiorum sicut non supponunt constantiam rei, sic nec supponunt oppositum, scilicet non-constantiam. Sed ens rationis divisum contra ens reale supponit 
ser objeto de opinião, ou seja, a tudo sobre o qual podemos formar um juízo ou uma proposição, indiferentemente à existência dos objetos significados. Seguindo uma passagem conhecida dos "Tópicos", segundo a qual o domínio da opinião é mais largo que aquele do ser, ${ }^{12}$ Odon conclui que os domínios dos entes reais e dos entes de razão (ou dos entes ficcionais, limitados ao espírito) não correspondem ao sujeito dos primeiros princípios. ${ }^{13}$ É manifesto que podemos falar a mesmo título das coisas reais como de privações ou de ficções, de eventos futuros ou de eventos passados. O problema que começa a tomar forma aqui e que será explorado logo adiante é o da referência vazia, ou seja, o problema de significar não-existentes e de formar proposições verdadeiras com os conceitos que os significam.

Opondo dessa maneira o ens reale ao ens rationis, Odon quer introduzir um terceiro nível na topologia do ente, comum ao real e ao mental e indiferente a todas as dicotomias do ser. O único candidato apropriado ao escopo dos primeiros princípios é, segundo Odon, o ente adjacente em terceiro [lugar] (ens tertio adiacens), ou seja, o ente significado pela composição proposicional.Essa identificação surpreendente se torna mais clara à medida que as propriedades desta entidade são apresentadas. A segunda metade do primeiro capítulo do tratado é inteiramente dedicada ao desenvolvimento dessa noção e de suas três funções lógicas, a saber: a função de cópula (esse tertio adiacens), a função de significado total da proposição (enuntiabile) e a função de sujeito próprio da lógica (entendido como seu objeto de investigação). Nós nos concentraremos sobre a segunda função lógica do ens tertio adiacens, procurando resumir nos próximos parágrafos suas características essenciais.

non-constantiam rei. Ut si dicatur 'formalis differentia vel est ens reale vel est ens rationis'; si ens reale, habet constantiam rei, si ens rationis, non habet constantiam rei. Quare ens rationis ut sic non est aliquid de terminis horum principiorum".

12 Aristóteles, "Tópicos", IV, 1, 121b1-2. Esta conclusão terá uma consequência surpreendente, que não poderemos explorar detalhadamente aqui: visto que o sujeito dos primeiros princípios ultrapassa o escopo dos entes reais, considerados pela tradição aristotélica como o sujeito da metafísica, Odon conclui que os princípios de não-contradição e de terceiro excluído não são propriamente metafísicos, mas se tratam de princípios lógicos, os quais podem ser utilizados pela metafísica quando esta considera seu próprio sujeito de investigação: o ens reale. Odon, 1997, I, §55, p. 347: "Respondeo quod hec non sunt principia metaphisica adequate".

13 Odon, 1997, I, §51, p. 346: "Uterque terminus horum principiorum extenditur ad omne subicibile et ad omne predicabile [...]. Sed ens reale non; patet quarto Topicorum quod opinabile communius est ente". Odon, 1997, I, §58, p. 348: "Item quia: quod non extenditur ad omne subicibile nec ad omne predicabile nec ad terminos cuiuslibet contradictionis nec ad terminos cuiuslibet conclusionis probate per hec principia non est terminus horum principiorum. Sed ens rationis est huius modi. Deus enim non est ens rationis, et tamen est acceptabilis ut subiectum et predicatum, ut terminus alicuius contradictionis, ut terminus alicuius conclusionis probate sive demonstrate per hec principia. Quare ens rationis ut divisum contra ens reale non est aliquis terminus horum principiorum". 
No que toca à cópula, Odon distingue duas propriedades: enquanto signo (in signo), ${ }^{14}$ o esse tertio adiacens nada mais é que a composição efetuada pela segunda operação do intelecto, a qual não pode ser entendida sem os extremos da proposição. ${ }^{15}$ Trata-se do verbo 'est' responsável pela predicação; ele corresponde à função tradicionalmente atribuída à locução 'esse tertium adiacens', oposta ao juízo existencial significado pelo mesmo verbo em secundum adiacens. ${ }^{16}$ Enquanto significado (in significato), o esse tertio adiacens é a união, a composição, a indivisão daquilo que é significado pelo predicado com aquilo que é significado pelo sujeito da proposição. ${ }^{17} \mathrm{O}$ verbo 'ser' não é, portanto, um sincategorema para Odon, pois ele carrega um significado próprio, suplementar à função copulativa. Essa indivisio estabelece a identidade da coisa-predicado com a coisa-sujeito, retirando toda a pluralidade do objeto de significação. ${ }^{18}$ Ela também é entendida como a identidade do sujeito com ele mesmo, a qual é anterior a toda significação (seja ela uma afirmação ou uma negação). Ora, toda proposição pressupõe seu sujeito, o qual pressupõe sua própria identidade. Com efeito, é ao utilizarmos o esse tertio adiacens que podemos afirmar a identidade de um não-ente consigo mesmo. Segundo Odon, o esse tertio adiacens in significato é pressuposto pela afirmação envolvendo uma privação: 'cegueira é cegueira' (cecitas est cecitas) ou ainda pela negação 'o não-ente não é um ente' (non ens non est ens). A identidade de algo consigo mesmo é sempre causa da verdade de uma negação a seu respeito: "é porque o homem é um homem que ele não é um asno, e não o contrário". ${ }^{19}$

14 Odon, 1997, I, §59, p. 348: "Pro evidentia conclusionum sequentium sunt aliqua prenotanda de esse tertio adiacenti et de ente dicto a tale esse. De esse primo notanda aliqua ut consideratur in signo, scilicet in conceptu et voce, aliqua ut in significato, scilicet in obiecto et re".

15 Odon, 1997, I, §60, p. 348: "[...] hoc verbum 'est' significat unionem seu compositionem predicati cum subiecto. Hoc habetur primo Peryarmenias a Philosopho dicente: 'est' quandam compositionem significat quam sine extremis non est intelligere. Extrema hic dicuntur subiectum et predicatum; compositio: unio eorum in oratione".

16 Cf. G. Nuchrelmans, 1992.

17 Odon, 1997, I, §67, p. 351: "Hoc esse in obiecto sui conceptus est unio, compositio et indivisio eius quod significatur per terminum predicatum cum eo quod significatur per terminum subiectum".

18 Odon, 1997, I, §67, p. 351: "[...] est quedam affirmatio seu compositio que ponit rem termini predicati cum re termini subiecti et cum hoc removet divisionem et negationem et pluralitatem consequentem".

19 Odon, 1997, I, §70, p. 352: "[...] huiusmodi esse presupponitur cuilibet negationi et cuilibet non-esse. Quod patet sic (ponendo quod homo est homo et quod homo non est asinus): Quia quidam homo est homo, ideo non est asinus, et non econverso. Non enim quia non est asinus, ideo est homo. Tunc enim equus, qui non est asinus, esset homo. Et patet in isto de quo minus videtur, scilicet de non-ente, cui Philosophus quarto Metaphisice attribuit istud esse. Unde cum dicitur 'non-ens non est ens', huic negationi presupponitur hec affirmatio 'non-ens est non-ens', quia cuicumque propositioni presupponitur subiectum; in isto autem subiecto continetur hec affirmatio seu indivisio subiecti a seipso. Et sic cuilibet negationi presupponitur affirmatio subiecti de seipso et, per consequens, illud esse de quo fit sermo, idest tertio adiacens". 
O esse tertio adiacens transpassa, assim, todos os níveis da significação, pois ele é subentendido já no nível simples da representação do sujeito (ou do predicado) da proposição, na medida em que ele deve poder expressar sua própria identidade. Por exemplo, em 'Sortes est albus', a identidade de Sócrates é subentendida e expressa de maneira complexa por uma afirmação (affirmatio subiecti de seipso): Sortes esse Sortes. Ora, o esse suposto pela identidade dos termos que formam a proposição não é outro senão o esse tertio adiacens.

Segundo Odon, é o esse tertio adiacens in significato que explica o adágio aristotélico: "assim como algo é com relação ao ser, ele é com relação à verdade" (Aristóteles, "Metafísica" II.1, 993b30-1), ou seja, a possibilidade de falar verdadeiramente de algo é proporcional ao seu ser. Para Odon, essa tese implica a seguinte consequência: tudo aquilo que é verdadeiro, é em certo sentido (e tudo aquilo que é necessariamente verdadeiro, é necessariamente). Por conseguinte, as afirmações 'non ens esse non ens' e 'cecitatem esse cecitatem', as quais são manifestamente verdadeiras, possuem ser, e isso ex parte obiectu, isto é, a partir daquilo que elas significam, pois a verdade recai sobre a proposição segundo o acordo entre o que ela diz ou significa e como a coisa é (ab eo quod res sic est sicut per orationem dicitur, oratio vera dicitur). O não-ente e a cegueira não podem constituir o fundamento da verdade das proposições que os tomam como sujeito/predicado, visto que eles não são. Deve haver, todavia, um esse que corresponda àquele da máxima 'verum sequitur esse rerum' e que autorize a convertibilidade entre ser, coisa e verdade nesses casos. Para Odon, o esse tertio adiacens é o único esse que pode ser e constituir o fundamento de afirmações verdadeiras sobre o não ser. ${ }^{20}$ A propriedade essencial desta forma de ser consiste em sua neutralidade ou indiferença com relação à existência.

Odon estava apresentando as características do ser copulativo. No restante do capítulo ele passa à representação do ente ao qual ele corresponde. Tratase de uma passagem surpreendente, pois ela mostra que a composição mental corresponde efetivamente a um tipo de entidade. Até este momento do tratado,

20 Odon, 1997, I, §72, p. 353: "[...] de hoc esse dicitur secundo Metaphisice quod unumquodque sicut se habet ut sit, sic se habet ad veritatem. Quod patet, quia de nullo alio esse potest <illud verbum> vere intelligi. Quod probo sic. Unumquodque sic se habet ad esse sicut se habet ad veritatem: habendo veritatem habet esse illud de quo hic agitur, et habendo necessario veritatem habet necessario esse, et non habendo veritatem non habet esse illud; et econverso. Sed non-ens esse non-ens et cecitatem esse cecitatem habent veritatem; et necessario habent eam ex parte obiecti, quia ab eo quod res sic est sicut per orationem dicitur, oratio vera dicitur. Sed hec ex parte obiecti non habent aliquod aliud esse, et maxime necessario, nisi istud quod est compositio seu indivisio non-entis cum non-ente, cecitatis cum cecitate. Quare de nullo alio esse potest vere intelligi verbum istud". 
falávamos do modo de ser implicado na cópula de uma proposição; agora, é o caso de apresentarmos o ens tertio adiacens, entendido como o significado total da proposição ou enunciável (enuntiabile): ${ }^{21}$ "o ente dito a partir do <esse tertio adiacens $>$ é como que um composto do sujeito e do predicado; e esse tipo de ente nada mais é que o todo enunciável pela proposição".

Odon entende o significado proposicional como um composto final, sem reduzi-lo ao composto de coisas reais significadas pelos seus termos ou a um terceiro elemento na realidade:

Deve-se notar primeiramente, a respeito do ente dito a partir do <esse tertio adiacens $>$, de que modo ele é obtido. Deve-se saber que, assim como dizemos que um composto é um agregado de matéria e forma (e da matéria composta com a forma e da forma composta com a matéria), assim também chamamos 'composto' uma proposição agregada de termos ou de seu significado total (e igualmente de quaisquer termos ou seus significados). Além disso, visto que essa composição não é uma união ou conjunção real, mas apenas uma indivisão, exclusão de divisão e separação, então não a inteligimos universalmente como existindo na realidade tal um terceiro agregado. (Odon, 1997, p. 354) $)^{22}$

O ens tertio adiacens é apresentado como possuindo cinco propriedades convertíveis: concebível, significável, predicável, passível de ser o sujeito em uma proposição e passível de ser oposto em uma contradição. ${ }^{23}$ Com efeito, o ens tertio adiacens é apresentado como um sinônimo de 'coisa' (res) na já citada definição aristotélica de verdade. ${ }^{24}$ Odon precisa que a noção de 'res' é tomada aqui logicamente, isto é, ela é tomada no sentido de 'eu penso' (res dicta a reor). ${ }^{25}$ Nós vemos nesta afirmação uma indicação de que Odon concebe o ens tertio adiacens inspirado pela distinção entre res a reor reris e res a ratitudine desenvolvida por Henrique Gandavo e retomada por Duns Scotus. ${ }^{26}$ Em curtas linhas, Gandavo concebeu a coisa pensável como o

21 Odon, 1997, Annexum III, §66, p. 485: "Secundum hoc ergo ens dictum a tali esse dicitur quasi compositum ex subiecto et predicato; et hoc modo ens nihil aliud est quam totum enuntiabile per enuntiationem".

22 Odon, 1997, ।, §75, p. 354: "De ente vero a tali esse dicto primo notandum est quomodo sumitur ab isto esse. Ubi sciendum quod, sicut compositum dicitur de aggregato ex materia et forma et dicitur de materia composita forme et de forma composita materie, sic omne compositum importans potest dici de propositione aggregata ex terminis sive de eius significato totali. Et potest dici de quolibet terminorum seu significato eorum. Tamen quia hec compositio non est realis unio vel coniunctio, sed solum indivisio et exclusio divisionis et separationis, ideo non intelligimus universaliter esse in rebus tale tertium aggregatum".

23 Odon, 1997, I, §77, p. 355: "Hiusmodi ens habet quinque proprietates secum convertibiles, scilicet conceptibile, significabile, subicibile, predicabile, contradictorie oppinabile".

24 Cf. Aristóteles, Categorias, 5, 4b8-10.

25 Odon, 1997, I, §82, p. 356: “Notandum tertio quod 'res' dicta a 'reor' et sumpta logicaliter, sicut ibi: 'ab eo quod res est, vel non est, oratio vera vel falsa dicitur', est idem convertibiliter cum ente sic sumpto; et sunt duo termini synonimi".

26 Cf. H. Gand, 1953, a. 21, q.4, fol. 127ro; SCOTUS, J. D. Scotus, 1968, q. 3, a.1, p. 114. 
ponto de partida do conhecimento (as definições nominais) ${ }^{27}$ indeterminado quanto à essência e no qual estão incluídos os seres ficcionais e impossíveis (bode-cervo, montanha dourada); a coisa no sentido ratificado corresponde aos exemplares divinos, dotados de essência, mas indeterminados quanto à existência, obtida somente após a criação. Scotus retoma essa distinção em suas questões quodlibetales separando-a do exemplarismo, ao mesmo tempo que identifica a coisa pensável, tomada no sentido amplo de aliquid, ao primeiro objeto adequado do intelecto.

De fato, o ens tertio adiacens compartilha o estatuto omni-englobante da coisa pensável, em especial o fato de ela abarcar tanto o real quanto o mental e ser identificada ao primeiro objeto adequado do intelecto (sendo que esta característica está somente presente na leitura de Scotus). A coisa lógica é, para Odon, comum a todo inteligível, indeterminada com relação à essência e à existência. Vimos que ela corresponde, ao mesmo tempo, ao sujeito dos primeiros princípios e ao verificador e significado último da proposição. A partir desses resultados, Odon pode identificar o sinônimo da coisa lógica, o ens tertio adiacens, ao sujeito próprio da lógica. A lógica trata, segundo Odon, de um domínio do ente absolutamente indeterminado, o qual compartilha o escopo de seus princípios e de suas conclusões.

No sexto capítulo do tratado, Odon conecta a primazia dos primeiros princípios ao primeiro objeto adequado do intelecto, ou seja, o domínio dos entes que corresponde às nossas capacidades intelectivas, que é proporcional ao espectro da intelecção humana. Nesse contexto, as propriedades convertíveis com o ens tertio adiacens (conceptibile, significabile, subicibile, predicabile, contradictorie opinabile) são identificadas ao primeiro objeto adequado do intelecto. ${ }^{28}$ A partir dessa identificação, Odon conclui surpreendentemente que a lógica é a ciência suprema, em razão da prioridade e da abstração absoluta de seu sujeito. Retomando as distinções dos primeiros objetos do intelecto introduzida por Duns Scotus (ordo originis, ordo perfectionis, ordo adaequationis $),{ }^{29}$ a ciência divina permanece primeira com relação ao primeiro

27 Segundo uma distinção bem conhecida entre os medievais, uma definição nominal (quid nominis), em oposição à definição real (quid rei), não define a essência ou a quididade de um ser. Com efeito, ela não se aplica exclusivamente às coisas das quais podemos afirmar a existência. Pode haver, assim, definições nominais de não-entes, como o bode-cervo e a quimera. Encontramos a mesma distinção em Odon quando este qualifica o sujeito dos primeiros princípios, os quais exigem tão somente a definição nominal dos termos empregados para serem compreendidos - esta é, a propósito, uma das razões pelas quais eles são ditos evidentes. Cf. Odon, 1997, I, §24, p. 428; §55, p. 347; §20, p. 453.

28 Odon, 1997, VI, §20-21, p. 427: "Obiectum enim primum intellectus cuiuscumque convertitur cum intentione ista 'intelligibile' vel 'conceptibile'. [...] prima propositio simpliciter formatur de obiecto intellectus primo simpliciter et universaliter".

29 Cf. J. D. Scotus, 1950, I, 3, §69. 
objeto do ponto de vista da perfeição, mas se existe uma primeira ciência no sentido absoluto, ela será a lógica. ${ }^{30}$

Nós podemos dizer, assim, que o ens tertio adiacens é o fundamento do discurso verdadeiro e significativo (isto é, não contraditório). Isso explica a identificação do sujeito dos primeiros princípios ao ens tertio adiacens: é em virtude do fato de que podemos falar verdadeiramente de modo nãocontraditório a respeito de tudo (daquilo que é e daquilo que não é, do possível e do impossível, do mental e do extramental) que os primeiros princípios ultrapassam os limites do ens reale e englobam os limites do ens rationis. Para Geraldo Odon, ao mesmo tempo que o objeto adequado do intelecto compartilha o escopo dos primeiros princípios, ele ultrapassa os limites do real (e a consideração do metafísico). Os únicos limites que não podem ser ultrapassados são impostos pela contradição, pois o contraditório é ininteligível.

Tendo em vista o que foi dito, podemos considerar Odon como um realista, em virtude da objetividade própria que ele confere ao objeto da significação, a coisa lógica, o ente composto que corresponde à cópula proposicional. Bem entendido, o "realismo proposicional" de Odon não deve ser entendido como um tipo de reísmo; nossa afirmação deve ser qualificada em função da indiferença com relação ao mental e ao extramental que define o ente que corresponde ao significado proposicional e ao sujeito dos primeiros princípios. $\mathrm{O}$ aspecto central dessa entidade é a sua abrangência, o fato de ela ser omni-englobante, anterior às dicotomias do ser.

\section{A propositio in re em Walter Burley}

Burley, filósofo inglês de orientação realista do início do século XIV, oferece uma explicação do estatuto do significado proposicional que compartilha aspectos marcantes da explicação odoniana. ${ }^{31}$ Para apresentar o realismo proposicional de Burley, limitar-nos-emos aos textos nos quais sua teoria da proposição se encontra mais elaborada e finalizada, a saber,

30 Odon, 1997, VI, §22-23, p. 427: "Et cum probatur quod scientia divina est prima scientiarum, verum est perfectione - de qua prioritate nichil ad proposiyum - sed loquendo de prioritate formali, secundum quam una scientia alteram presupponit formaliter, sic dico quod logica est simpliciter prima scientiarum omnium, de cuius subiecto primo hec principia formata sunt. [...] quod autem logica sit simpliciter prima scientiarum omnium probatur primo ex eius communitatem [...]. Sed logica est omnium scientiarum communissima, ut patet, quia est de obiecto communissimo [...] ergo est simpliciter prima".

31 Para os principais trabalhos sobre a proposição em Burley, cf. L. Cesalli (2001, pp. 155-221); do mesmo autor, o já citado "Réalisme propositionnel" (2007a); J. Biard, 2003a, pp. 103-118; J. Biard, 2003b, pp. 81105. 
no comentário à logica vetus de 1337, em particular o comentário ao "Perihermeneias" e o comentário às "Categorias". ${ }^{32}$

No início do mencionado comentário ao "Perihermeneias", Burley trata da questão da definição da proposição e da noção de 'adequatio rei' que intervém na sua verificação, isto é, a ideia de correspondência da composição (ou divisão) expressa pela proposição mental à composição (ou divisão) presente da realidade. Ao refletir sobre a complexidade da proposição mental e sobre o dispositivo que a torna verdadeira ou falsa, Burley se pergunta i) se se deve dizer que há proposições compostas de coisas extramentais, ${ }^{33} \mathrm{e} \mathrm{ii)} \mathrm{se}$ sim, em qual sentido devemos tomar a noção de 'coisa' implicada.

Burley responde afirmativamente à primeira questão ${ }^{34} \mathrm{Um}$ argumento importante é desenvolvido no comentário às "Categorias": para escapar a uma regressão ao infinito, a ordem de significação deve encontrar um ponto final. Ora, tudo aquilo que significa deve ter em última instância um significado que não significa nada ulterior. Assim, a proposição escrita significa a proposição vocal, a qual significa a proposição mental (in conceptu). Resta saber se a proposição mental significa algo ulterior ou se ela constitui o termo final na cadeia de significação. Burley responde que não, pois visto que os conceitos que compõem a proposição mental significam algo, então a totalidade da proposição significa igualmente algo, a saber, o significado total e adequado da proposição, uma vez que aquilo cujas partes significam deve ele próprio significar. ${ }^{35}$

Neste momento, a questão que se coloca visa à natureza do significado da proposição mental. Primeiramente, é claro para Burley que ela deve ser complexa, visto que a proposição mental possui uma estrutura complexa (sujeito-cópula-predicado). A proposição mental significa, assim, um

32 Burley, 1497. O comentário às "Categorias" ocupa os fol. 15va-44vb; o do "Perihermeneias" os fol. 57ra82 rb.

33 Burley, 1497, fol. 58rb: "Sed utrum sit aliqua propositio composita ex rebus extra animam".

34 Burley, 1497, fol. 58rb: "Supposito vero quod non sit aliqua propositio in re composita ex rebus, ut communiter dicitur, est dubium quid ex parte rei correspondeat veritati et falsitati propositionis in mente et in prolatione. Oportet enim quod ei correspondeat aliquid in re per quod tunc dicamus quod verum est quod propositio in mente et in prolatione est vera, quia sic significat sicut est in re. Ad hoc igitur quod propositio sit vera oportet quod sit in re sicut propositio significat et per consequens veritati propositionis in mente et in voce et in scripto correspondet aliquid proportionale".

35 Burley, 1497, fol. 15vb-16ra: "[...] in omnibus significantibus et significatis et ordinatis in significando est devenire ad ultimum significatum, quod ita significatur quod ulterius non significat. Aliter esset processus in infinitum in essentialiter ordinatis contra Philosophum. Sed propositio in scripto significat propositionem in voce, propositio in voce significat propositionem in conceptu, scilicet propositionem compositam ex conceptibus. Quero tunc aut propositio composita ex conceptibus sit ultimum significatum, scilicet quod ulterius non significat, aut significat aliquid ulterius. Non est dare primum, quia conceptus ex quibus propositio componitur in mente significant. Igitur tota propositio composita ex conceptibus significat. Cuius enim partes significant, et ipsum totum significat". 
compositum. Deve-se indagar agora se esse composto é formado de conceitos ou de coisas. A mesma razão pela qual havíamos dito que a proposição mental não é o significado último na cadeia de significação intervém aqui: os conceitos são, por definição, signo de algo; assim, para que a significação não proceda ao infinito, o significado último deve ser composto de coisas, e não de conceitos. ${ }^{36}$ Assim sendo, Burley procura claramente uma via realista ao sustentar que o significado da proposição é algo para além do mental, algo composto de coisas extramentais. Para ele, se as proposições falam das coisas (em detrimento de palavras ou conceitos), o fundamento da verdade deve se encontrar no extramental, e, por conseguinte, as proposições devem encontrar um significado último in re. O significado final e adequado da proposição deve ser assim uma propositio in re, a qual possui uma natureza heterogênea: um elemento mental (a cópula que resulta da segunda operação do intelecto) e dois elementos extramentais (sujeito e predicado).

Toda a dificuldade se resume agora na determinação do sentido no qual devemos tomar a noção de 'res' implicada na expressão 'propositio in re'. A resposta passa por uma dificuldade intermediária, a saber, a de explicar a verdade de proposições sobre não-existentes, ou seja, a verificação de proposições sem referentes. Para tanto, Burley lançará mão de uma nova noção: 'ens maxime transcendens'.

O lógico inglês passa a enfrentar "problemas de referência vazia". A questão é colocada na forma de uma objeção que mostra a inviabilidade entre uma explicação da verdade proposicional em termos de identidade e diferença entre os supostos (ou referentes) do sujeito e do predicado quando estes não existem:

E se é dito que há uma proposição afirmativa verdadeira quando não há identidade <entre o sujeito e o predicado>, pois esta proposição é verdadeira: 'César é César' enquanto que não há identidade; igualmente, a negativa pode ser verdadeira sem que haja diversidade entre aquilo pelo qual o sujeito e o predicado supõem, como é patente. Esta proposição também é verdadeira: 'César não é Platão', enquanto que

36 Burley, 1497, fol. 16ra: "Quero tunc de illo quod significatur per propositionem in mente compositam ex conceptibus: illud non potest esse simplex, quia partes propositionis significant incomplexe, et illud quod significatur per totam propositionem est complexum. Ergo illud est compositum. Aut ergo illud est compositum ex conceptibus aut ex rebus. Si ex rebus, habeo propositum scilicet quod propositio componitur ex rebus. [...] Si sit compositum ex conceptibus, tunc cum conceptus significent et non sunt ultimum significatum, querendum est de significato illius compositionis ex conceptibus sicut prius. Et sic vel procedendum est in infinitum, vel tandem est devenire ad aliquod compositum ex rebus quod est ultimatum significatum propositionis in prolatione [et] in mente". 
César e Platão não são < coisas > diferentes, visto que não são entes, e ser o mesmo e ser diferente são distinções do ente. (Burley, 1497, fol. 58rb) (37 $^{37}$

A resposta de Burley consiste em negar a premissa maior do objetor, segundo a qual há apenas identidade entre entes existentes. Para isso, o sentido de 'ente' será estendido no interior de uma distinção:

Deve-se dizer que com respeito a César morto [corrupto], há identidade entre César e César, porém essa identidade não existe, mas é uma identidade de razão [identitas rationis]. Para <que haja $>$ identidade entre César e César não é exigido que a identidade e a diversidade sejam sempre distinções do ente < real, mas do ente> maximamente transcendental, o qual se encontra no intelecto. A partir disso, podemos dizer que o ente se diz de duas maneiras: (i) como comum a todo inteligível e (ii) como existente. De maneira análoga, por um lado a identidade e a diferença são consideradas distinções do ente $<$ maximamente $>$ transcendental, por outro lado, elas são consideradas distinções do ente existente em ato. (Burley, 1497, fol. 58rb) ${ }^{38}$

Assim, a relação de identidade não se dá apenas entre entes reais, mas pode se dar entre inteligíveis, ou seja, entes tomados no sentido mais comum possível, o qual não implica existência atual. Bem entendido, quando Burley fala de inteligíveis, ele não está falando de conceitos no intelecto, pois nesse caso voltaríamos ao nível da proposição mental (e à ameaça de regressão ao infinito). 'César' significado na proposição verdadeira 'César é César' não é um conceito nem um ens reale, mas um ens maxime transcendens. A res que verifica essa categoria de proposições deve ser tomada como um inteligível. Nossa atenção se voltará, assim, sobre o ens maxime transcendens e ao 'alargamento' da noção ente que ele revela.

\section{Ens maxime transcendens}

Procurando explicar como podemos predicar termos que não possuem referentes, Burley precisa qual tipo de ente corresponde aos seus referentes. Isso é o mesmo que responder à questão: do que a propositio in re é formada

37 Burley, 1497, fol. 58rb: "Et si dicatur quod est affirmativa vera quando non est talis identitas quia hec est vera 'Caesar est Caesar' et tamen non est aliqua identitas, similiter negativa potest esse vera sine tali diversitate illorum pro quibus supponit subiectum et predicatum, ut patet. Ista enim est vera 'Caesar non est Plato' et tamen Caesar et Plato non sunt diversa cum non sint entia et idem et diversum sunt differentie entis".

38 Burley, 1497, fol. 58rb: "Dicendum quod Caesare corrupto identitas est Caesaris ad Caesarem, sed illa identitas non existit, sed est identitas rationis. Et idem Caesarem (sic) idem Caesari identitate quae non est nec oportet quod idem et diversum semper sint differentie entis <existentis sed entis > maxime transcendentis quod scilicet est in intellectu. Unde sic potest dici, quod ens dicitur dupliciter: uno modo ut est commune omni intelligibili, alio modo idem est quod existens. Sic idem et diversum dicitur uno modo ut sunt differentie entis transcendentis, alio modo ut sunt differentie entis in effectu, hoc est in actu existentis". 
no caso de proposições não-standards? Compreender o estatuto da propositio in re nesses casos é o mesmo que compreender a natureza do ens maxime transcendens. Essa noção é apresentada com mais detalhes em outros textos de Burley, em especial no pequeno tratado intitulado De ente. Neste texto, a distinção do ente é tomada triplamente. Burley começa explicando que podemos distinguir níveis de transcendência: podemos falar de noções mais transcendentais, de noções menos transcendentais e de noções maximamente transcendentais. Com efeito, o ente comum às dez categorias é mais transcendente que a substância, a qualidade e a quantidade. Para além do ente transcendental haveria o ente comum a todo inteligível (commune omni intelligibili), o qual opera um segundo movimento de transcendência, pois ele envolve o ente comum às categorias. ${ }^{39}$

$\mathrm{Na}$ sequência do texto, Burley retoma essa divisão tripla precisando suas extensões. ${ }^{40} \mathrm{O}$ ente que corresponde ao objeto adequado do intelecto ${ }^{41}$ (as primeiras impressões da alma das quais fala Avicena ${ }^{42}$ ) é chamado aqui ens intelligibile, ou ens in intellectu. Nesse sentido, 'ens' e 'intelligibile' são convertíveis, assim como 'homem' e 'racional' são convertíveis. ${ }^{43}$ Todo inteligível é um ente e vice-versa. Ele corresponde a tudo aquilo que pode ser objetivamente, ou seja, tudo que pode ser objeto de um pensamento. O ens intelligibile é entendido nominalmente e é tão largo que ele não possui oposto: ele é omni-englobante, pois é uma noção cujo sentido é completamente indeterminado. ${ }^{44}$

39 Burley, 1964, p. 106: "Item intelligendum quod illud dicitur transcendens quod est commune diversis predicamentis. Verbi gracia: omne absolutum est transcendens quia est commune tribus predicamentisut substancie, qualitati et quantitati. Similiter omne respectivum est transcendens septem predicamentis; et illud quod est commune omnibus predicamentis est transcendens, et est magis transcendens quam illud quod est commune aliquibus predicamentis et non aliis. Et ideo transcendens recipit comparacionem quia aliquid est magis transcendens, et aliquid minus, et aliquid maxime. Verbi gracia: absolutum est ens transcendens; et ens quod est commune per se decem predicamentis; et ens quod est commune omni intelligibili est maxime transcendens".

40 Burley, 1964, p. 108: "Sic ergo patet quod 'ens' et 'existens' accipiuntur tripliciter: uno modo ut est obiectum adequatum intellectus modo quo dictum est - et sic dicitur ens intelligibile, sive ens in intellectu, quia omne ens, sic accipiendo 'ens', est in intellectu vel esse potest obiective. Secundo modo dicitur 'ens' cui non est esse prohibitum. Et ens isto modo dicitur 'ens' in suis causis. Tertio modo dicitur 'ens' ut est participium, et sic dicitur ens in se, vel in effectu. Ens primo modo non habet oppositum, nec potest infinitari, ut dictum est. Sed ens secundo modo et tertio modo dictum habet oppositum et potest infinitari, et sic sicut distinguitur de ente, ita de non-ente, aut de nichilo. Duobus autem modis dicitur 'nihil', aut quasi est esse prohibitum, ut vacuum vel chemera. Alio modo dicitur 'nihil' quod non existit in effectu, et sic Antichristus dicitur nihil. Eodem modo est de non-ente, etc.".

41 Podemos ver aqui novamente a influência da já mencionada distinção de Duns Scotus.

42 Avicena, Liber de Philosophia Prima, I, 5, p. 31-3.

43 Burley, 1964, p. 107: "Et isto modo ens quod est maxime transcendens est obiectum adequatum intellectus secundum Avicennam, nam omne ens est cognoscibile ab intellectu, et omne cognoscibile ab intellectu est ens; et isto modo isti termini 'ens' et 'intelligibile' sunt termini convertibiles sicut 'homo' et 'racionale"'.

44 Burley, 1964, p. 107: "Et isto modo ens accipitur nominaliter, et non habet oppositum [...]". 
Burley entende o segundo e o terceiro sentido do ente (ens in suis causis, ens in effectu ou ens existens ${ }^{45}$ ) em oposição ao esse prohibitum, isto é, em oposição ao nada, ao vácuo e às ficções. Podemos entender o nada (nihil) de duas maneiras: como um ser impossível (como a quimera e o vazio), ou como um ser possível, mas inexistente (quod non existit in effectu), e neste caso podemos dizer que César ou o anticristo são não-entes. O restante do texto nos autoriza a localizar o ens prohibitum no escopo do ens intelligibile: "tomando dessa maneira o ente <maxime transcendens $>$ isto é verdadeiro 'a quimera é um ente' e 'o vácuo é um ente', e tomando dessa maneira $<$ o ente ao qual o ser não é proibido, ens in suis causis $>$, nenhuma rosa existindo, isto é verdadeiro: 'a rosa é um ente'". ${ }^{46}$

Assim, podemos dizer que, segundo Burley, o ente que corresponde ao objeto adequado do intelecto é comum ao ens rationis (ficções inclusas) e ao ens reale. Os não-entes se encontram excluídos dos sentidos menos comuns do ente, enquanto que o ens intelligibile os envolve. É a partir dos dois sentidos mais comuns do ente que podemos formar proposições verdadeiras sobre nãoexistentes, ou seja, proposições com referência vazia. Para as proposições que falam sobre não-ente passível de ser, o segundo sentido é implicado; enquanto que para aquelas que falam de não-entes aos quais o ser é proibido, o ente transcendente ao ponto mais elevado é implicado. Enfim, para os casos de proposições verdadeiras que envolvem existência, o ens in effectu é visado. $\mathrm{O}$ mesmo raciocínio se aplica à afirmação de identidade 'César é César', a qual envolve o ente in suis causis.

Podemos neste momento aproximar as passagens do "De ente" ao problema do significado proposicional. A solução da dificuldade levantada pela proposição 'César é César' consiste justamente em distinguir os diversos sentidos do ente e aplicá-los à propositio in re, a qual verifica se a proposição mental 'César é César' deve ser entendida como um composto de inteligíveis possíveis. Neste sentido ela mesma é um certo inteligível, na medida em que copula dois entes maximamente transcendentes. Isso nos leva a matizar o qualificativo 'in re' do significado último de toda proposição verdadeira igualmente para a noção de 'res' na fórmula 'ex eo quod res est vel non est oratio vera vel falsa dicitur'. Ela não equivale à coisa real, pois podemos significar, predicar, afirmar a identidade de coisas que não existem, e, em

45 Burley, 1964, p. 108: "Accipiendo vero ens prout est participium, sic solum dicitur de existentibus in effectu, ita quod 'ens' et 'existens' convertuntur".

46 Burley, 1964, p. 108: "Isto modo [maxime transcendens] enim accipiendo ens est hec vera: 'chimera est ens', 'vacuum est ens', et sic de quocumque alio intelligibili. [...] Et isto modo [illud cui non est esse prohibitum], nulla rosa existente in actu, hec est vera: 'rosa est ens'". 
consequência, ela deve se aplicar indiferentemente àquilo que é e àquilo que não é, ao mesmo tempo que mantém seu estatuto de ente extramental e de verificador. Para Burley, assim como para Odon, este é o caso da proposição 'non-ens est non-ens', a qual é manifestamente verdadeira e corresponde, com efeito, a uma res que a verifica. ${ }^{47}$

\section{Conclusão}

Nós vimos em nossa apresentação de Geraldo Odon que o ens tertio adiacens ou a res tomada logicamente cumpre o papel de significado total e verificador proposicional, e que sua principal propriedade que a torna apta a essa função lógica é sua indiferença ao l'esse existere. O ens tertio adiacens é definido por seu escopo omni-englobante; ele é um modo prévio do ser, o qual é somente limitado pela contradição. Os primeiros princípios da lógica são constituídos por essa entidade, a qual é convertível com a própria inteligibilidade - ou melhor, com o seu ponto de partida. Com efeito, a distinção entre ens reale, ens rationis e ens tertio adiacens se reduz à distinção entre esse existentiae, esse in anima tantum e esse intelligibile. Vimos também que, como outros lógicos medievais de tendência realista, Odon considera necessário identificar o significado da proposição a uma entidade especial que possa se elevar para além das dicotomias tradicionais do ser transcendental. Esse é o caso do ens maxime transcendens de Burley, quando presente na propositio in re. Para estes dois filósofos, o significado proposicional não consiste em uma entidade linguística nem mental, mas de uma entidade extramental independente da intelecção humana ${ }^{48}$ : é uma coisa pensável, não uma coisa pensada - não se trata de um esse obiective. A necessidade de postular uma entidade omni-englobante no interior de uma teoria da proposição procura dar conta dos casos de referência vazia, vistos como casos limites do discurso significativo. Esses casos não-standards da significação motivaram ambos os lógicos a seguirem uma tendência comum: o alargamento da noção de 'ens' e da noção de 'res'.

47 Burley, 1497, fol. 42ra-b: 'Intelligendum quod cum dicitur 'ex eo quod res est vel non est' et cetera, Philosophus non intelligit rem significatam per subiectum nec rem significatam per predicatum quia de non ente vere predicatur aliquid tanquam de subiecto, quia de non ente verum est dicere ipsum esse non ens, et ita propositio affirmativa potest esse vera quamvis res significata per predicatum sit non ens".

48 Para o problema de saber se, tanto em Odon como em Burley, o ens intellegibile encontra-se no intelecto divino ou se estaríamos diante de "terceiro reino" nas linhas de Frege, conferir nossa tese "La primauté de l'étant et les premiers principes chez Gérard Odon", Université de Paris IV-Sorbonne, 2014 (a ser publicada); cf. L. Cesalli, 2007b, pp. 283-297. 


\section{Referências}

ARISTÓTELES. "Categorias". In: L. Minio-Paluello (ed.), Categoriae vel Praedicamenta, translatio Boethii, (Aristoteles Latinus, I, 1-5). Bruges/Paris: Desclée de Brower, 1961.

ARISTÓTELES. "Metafísica". In: G. Vuillemin-Diem (ed.), Metaphysica: lib. I-XIV: recensio et translatio Guillelmi De Moerbeka (Aristoteles Latinus, XXV.3-2). Bruges/ Paris: Desclée de Brower, 1995.

ARISTÓTELES, “Tópicos”. In: L. Minio-Paluello (ed.). Topica, translatio Boethii, fragmentum recensionis alterius et translatio anonyma (Aristoteles Latinus V.1-3), Bruges/Paris: Desclée de Brower, 1969.

AVICENA, "Liber de philosophia prima sive scientia divina". In: S. Van Riet (ed.), Leiden/Brill/Louvain: Brill, 1977.

BERMON, P. “L'assentiment et son objet chez Grégoire de Rimini”. Paris: Vrin, 2007. BIARD, J. "Logique et théorie du signe au XIV` siècle". Paris: Librairie Philosophique J. Vrin, 1989.

BIARD, J. "Le statut des énoncés dans les commentaires du Peri hermeneias de Gautier Burley". In: H. Braakhuis, C. Kneepkens (eds.), 2003a.

BIARD, J. "Le réalisme de Gauthier Burley: logique, métaphysique, épistémologie". In: Cahiers de Philosophie de l'université de Caen, Vol. 38-39, 2003b.

BIARD, J. "Les controverses sur l'objet du savoir et les complexe significabilia à Paris au XIV siècle". In: S. Caroti, J. Celeytette (eds.), 2004.

BRAAKHUIS, H. A. G.; KNEEPKENS, C. H. (eds.). "Aristotle's Peri hermeneias in the Latin Middle Ages". Groningen-Haren, 2003.

BURLEY, W. "Liber Perihermeneias". In: Super Artem Veterem Porphyrii et Aristotelis. Venise, 1497.

BURLEY, W. "Liber Predicamentorum". In: Super Artem Veterem Porphyrii et Aristotelis. Venise, 1497.

BURLEY, W. "De ente”. In: H. Shapiro, "Walter Burley's De ente". Manuscripta, v. 7, 1964.

CAROTI, S.; CELEYTETTE, J. (eds.). “Quia inter doctores est magna dissensio: Les dé bats de philosophie naturelle à Paris au XIVe siècle". Firenze: L. S. Olschki, 2004. CESALLI, L. "Le réalisme propositionnel de Walter Burley". Archives d'Histoire Doctrinale et Littéraire du Moyen Âge, Vol. 68, 2001.

CESALLI, L. "Le réalisme propositionnel: sémantique et ontologie des propositions chez Jean Duns Scotus, Gauthier Burley, Richard Brinkley et Jean Wyclif". Paris: Vrin, 2007a.

CESALLI, L. "Intentionality and Truth-Making: Augustine's Influence on Burley's and Wyclif's Propositional Semantics". Vivarium. Vol. 45, Nr. 2, $2007 \mathrm{~b}$.

DUBA, W.; SCHABEL, C. “Gerald Odonis, 'doctor Moralis' and Franciscan Minister General: Studies in Honour of L.M. De Rijk”. Leiden: Brill, 2009. 
GAND, H. de. "Summae quaestionum ordinariarum", in aedibus I. Badii Ascensii, Parisiis, 1520. Reprinted. In: E. M. BUYTAER, E. M. St. Bonaventure, N. Y: Franciscan Institute, 1953.

LIBERA, A. de. "La référence vide: théories de la proposition". Paris: Presses Universitaires de France, 2002.

NUCHRELMANS, G. "Secundum/tertium Adiacens: Vicissitudes of a Logical Distinction". Amsterdam: Koninklijke Nederlandse Akademie van Wetenschappen, 1992.

ODON, G. "De duobos communissimis principiis scientiarum". In: Opera philosophica. Vol. I: "Logica", Livro III. L. M. de Rijk (ed.). Leiden: Brill, 1997.

SCHABEL, C. "The Sentences Commentary of Gerardus Odonis, O.F.M". Bulletin de Philosophie Médiévale, Vol. 46, 2004.

SCOTUS, J. D. "Quaestiones quodlibetas". In: Wadding (ed.). Opera Omnia, Vol. XXV, Lyon, 1639. Reprinted in: Hildesheim: G. Olms, 1968.

SCOTUS, J. D. “Ordinatio”. In: Opera Omnia, cura et studio commissionis scotisticae, v. III, Civitas Vaticana: Typis Polyglottis Vaticanis, 1950. 